\title{
CORPOS ESTRANHOS EM PRIMEIROS SOCORROS: REVISÃO INTEGRATIVA
}

\author{
Patrício de Almeida Costa1, lara Mayanne de Castro Araújo ${ }^{1}$, Eduarda Layane \\ da Silva Buriti ${ }^{1}$, Ana Elza Oliveira de Mendonça ${ }^{2}$, Adriana Montenegro de \\ Albuquerque ${ }^{3}$ \\ 1 Graduando (s) do Curso de Bacharelado em Enfermagem, Unidade Acadêmica de \\ Enfermagem, Universidade Federal de Campina Grande, Cuité-PB, Brasil. \\ 2 Pós-doctor em Enfermagem, Departamento de Enfermagem da Universidade Federal do Rio \\ Grande do Norte, Natal-RN, Brasil \\ 3 Doutora, Unidade Acadêmica de Enfermagem da Universidade Federal de Campina Grande, \\ Cuité-PB, Brasil \\ E-mail para correspondência: patricioalmeida13@hotmail.com
}

\begin{abstract}
Resumo
Objetivo: Identificar na literatura as publicações sobre condutas de primeiros socorros em corpos estranhos. Metodologia: revisão integrativa, realizada nas bases de dados Lilacs e Pubmed, por meio dos descritores primeiros socorros; corpos estranhos; e acidentes, nos idiomas português, inglês e espanhol correlacionados pelo operador booleano and. Dos 479 estudos encontrados, a partir do recorte temporal de 14 anos, apenas 9 artigos compuseram a amostra. Resultados: Dos achados, $11,1 \%$ correspondia à temática corpos estranhos em olhos; $33,3 \%$ boca e/ou garganta; $11,1 \%$ no ouvido; $33,3 \%$ nariz. E, $11,1 \%$ tratavam mutuamente de todas as temáticas. Sobre o idioma, a prevalência foi o inglês, com $55,5 \%$ dos achados, espanhol $(33,3 \%)$ e português $(11,1 \%)$. O periódico mais utilizado foi o Lilacs, correspondendo a $55,5 \%$ da amostra e PUBMED com $44,4 \%$. No que diz respeito ao Nível de evidência das obras sumarizadas, obteve-se majoritamente o nível IV, com apenas um nível V, o qual é justificado mediante a escassez de publicações. As principais condutas foram categorizadas e descritas em quatro subcategorias. Conclusão: Observa-se a escassez de estudos sobre a temática, sendo informações significativas para a agregação de conhecimentos e construção de novos trabalhos.
\end{abstract}

Palavras-chave: Corpos estranhos; primeiros socorros; acidentes.

\section{Abstract / resumen / résumé}

Objective: To identify in the literature publications on first aid procedures in foreign bodies. Methodology: integrative review, carried out in the Lilacs and Pubmed databases, using the first aid descriptors; foreign bodies; and accidents, in Portuguese, English and Spanish, correlated by the Boolean operator and. Of the 479 studies found, from the time frame of 14 years, only 9 articles made up the sample. Results: Of the findings, $11.1 \%$ corresponded to the theme foreign bodies in eyes; $33.3 \%$ mouth and / or throat; $11.1 \%$ in the ear; $33.3 \%$ nose. And, $11.1 \%$ treated each other mutually. Regarding the language, the prevalence was English, with $55.5 \%$ of the findings, Spanish (33.3\%) and Portuguese (11.1\%). The most used journal was Lilacs, corresponding to $55.5 \%$ of the sample and PUBMED with $44.4 \%$. 


\begin{abstract}
With regard to the level of evidence of the summarized works, the level IV was mostly obtained, with only one level V, which is justified by the scarcity of publications. The main conducts were categorized and described in four subcategories. Conclusion: There is a scarcity of studies on the subject, with significant information for the aggregation of knowledge and the construction of new works.
\end{abstract}

Keywords: Foreign bodies; first aid; accidents.

\title{
1 Introdução
}

Os primeiros socorros são as ações inicias e imediatas direcionadas à vítima, de qualquer faixa etária, em qualquer ambiente, com exceção ao hospitalar, realizadas com a finalidade de garantir a vida, proporcionar bem estar e, principalmente, evitar agravamento das lesões existentes. Quando realizado de maneira adequada, a taxa de sobrevida é elevada e traumas e sequelas podem variar em grau e gravidade (MEIRELES, 2014; RODRIGUEZ, et al., 2017).

Prestar socorro vai muito além de colocar em prática procedimentos de primeiros socorros, é necessário um olhar crítico e um conhecimento predeterminado, a fim de analisar o local onde a vítima se encontra, avaliar seu estado, avaliar situações prioritárias e solicitar ajuda, uma vez necessário. Para realizar as práticas de primeiros socorros sem oferecer risco a vítima, é importante que exista uma capacitação prévia, seja por cursos ou treinamentos, mesmo que este treinamento não faça parte de sua profissão. (RAGADALI FILHO et al., 2015; RUIZ et al., 2018).

Segundo Amaral et al. (2019) os acidentes por causas externas acontecem cotidianamente de forma inesperada, em sua grande maioria em ambiente domiciliar, sendo uma das principais ocorrências que necessitam um atendimento prévio de primeiros socorros. São caracterizados por lesões, traumatismos ou agravos à saúde, sejam eles intencionais ou não, englobando lesões provocadas por agressões, quedas, queimaduras, afogamento, envenenamento e ocorrências provocadas por circunstâncias ambientais como térmica, química, mecânica e energia elétrica.

No tocante as ocorrências provocadas por circunstâncias ambientais, os acidentes por corpos estranhos mostram-se um problema cada vez mais frequente e potencialmente grave. Sua prevalência está ligada a crianças menores de três anos, característico da faixa etária, podendo acarretar obstrução vias aéreas, comprometimento ocular, asfixia e morte, a depender do tipo de corpo estranho e local. Já em adultos, onde a incidência é menor, os 
casos podem ter origem proposital ou acidental, sendo os casos acidentais mais frequentes, relacionados em sua grande maioria, por insetos que penetram nas fossas nasais, ouvido, engasgos ou acidentes de trabalhos relacionados ao globo ocular (AMARAL et al, 2019).

Diante da alta incidência e importância dos primeiros socorros como finalidade de garantia do bem-estar, sobrevida e diminuição de complicações, o presente estudo tem como objetivo identificar na literatura as publicações sobre condutas de primeiros socorros em corpos estranhos

\section{Metodologia}

Trata-se de uma revisão de integrativa, realizada por meio de um levantamento eletrônico, no qual as principais fontes utilizadas foram as bases de dados Literatura Latino-Americana e do Caribe em Ciências da Saúde (LILACS) e Pubmed. Estudos de revisão integrativa tem apresentado destaque nas pesquisas em saúde, no qual é considerado um método relevante da análise de publicações da literatura, possibilitando a síntese do estado de conhecimento de um determinado tema, além de apontar lacunas do conhecimento que precisam ser preenchidas com a realização de estudos originais (SOUZA; SILVA; CARVALHO, 2010).

Neste artigo, adotam-se os termos "Primeiros Socorros" e/ou "Corpos Estranhos" como critério de inclusão nos achados metodológicos que compõem os resultados do estudo, estando relacionados à temática. Incluídos artigo em português, inglês e espanhol, e excluídos àqueles repetidos entre as bases de dados. A delimitação temporal dos artigos selecionados nos periódicos considerou o período dos últimos 14 anos de publicação empregando as seguintes etapas para consolidar a revisão: 1) Definição da temática de interesse; 2) formulação da pergunta norteadora "Quais as medidas de primeiros socorros para corpos estranhos nos olhos, boca, nariz e garganta ?" 3) Estabeleceu-se o cruzamento a partir dos descritores nos três idiomas: Primeiros socorros (primeros auxílios; first aid), corpos estranhos (cuerpos estraños; strange bodies) e acidentes (accidentes; accidents), correlacionados a partir do operador booleano "and" nas bases de dados selecionadas; 4) Seleção dos artigos relacionados com a temática e que atendiam os critérios de inclusão; 5) 
Recorte das informações extraídas ao longo das leituras dos artigos já existentes nas bases de dados; e 6) Elaboração de todos os elementos textuais a partir das informações extraídas (MENDES; SILVEIRA; GALVÃO, 2008).

No que se refere à seleção dos artigos foram respeitadas as seguintes etapas: utilização dos critérios de inclusão, seguida, pela leitura prévia dos títulos das publicações; leitura dos resumos em relação com a temática proposta; por fim, leitura dos artigos na íntegra.

Ademais, foi adotado como componente de análise, o nível de evidência das publicações sumarizadas e selecionadas para compor a amostra, seguindo a seguinte classificação: Nível I - revisão sistemática ou metanálise de múltiplos estudos controlados; Nível II - estudo individual com delineamento experimental; Nível III - estudo com delineamento quase-experimental como estudo sem randomização com grupo único pré e pós-teste, séries temporais ou casocontrole; Nível IV - estudo com delineamento não experimental como pesquisa descritiva correlacional e qualitativa ou estudos de caso; Nível V - relatório de casos ou dado obtido de forma sistemática, de qualidade verificável ou dados de avaliação de programas; e o Nível VI - opinião de autoridades respeitáveis baseada na competência clínica ou opinião de comitês de especialistas, incluindo interpretações de informações não baseadas em pesquisas (MELNYK; FINEOCT-OVERHOLT, 2005).

Ao fazer o cruzamento nas bases de dados utilizadas observou-se como número inicial 479 artigos, onde ao ser filtrado esse número sofreu uma redução para 64 artigos que foram criteriosamente analisados restando uma amostra de nove artigos, estes considerados aptos e relevantes a temática os quais constituíram a amostra final do estudo.

Para melhor organização e compreendimento foi realizado a construção de um quadro, no qual a sumarização dos artigos concedeu uma codificação da delimitação da amostra recebendo cada artigo um número (exemplo: A1, A2, A3...), outros aspectos que embasaram a pesquisa e estão dispostos no quadro são: número do artigo, ano, idioma, delineamento metodológico, base de dados, título, objetivo do estudo, principais resultados e nível de evidência. 
Os dados foram analisados e apresentados em forma de tabelas, discutidas em quatro categorias, no qual todos os processos realizados na construção do artigo pelos autores respeitaram os aspectos éticos e etapas supracitadas.

\section{RESULTADOS E DISCUSSÃo}

A amostra final do estudo foi composta de nove artigos, de um universo de 479 artigos, extraídos de dois periódicos diferentes. Para melhor visualização, os artigos foram distribuídos em duas tabelas. A tabela 01 dispõe da categorização dos artigos composto por: número do artigo, ano, idioma, tipo de estudo, base de dados e nível de evidência (NE).

Tabela 01: Categorização dos artigos em: codificação; ano; tipo de estudo; base de dados e NE.

\begin{tabular}{|c|c|c|c|c|c|}
\hline No & ANO & IDIOMA & $\begin{array}{r}\text { TIPO DE } \\
\text { ESTUDO }\end{array}$ & $\begin{array}{c}\text { BASES } \\
\text { DE } \\
\text { DADOS }\end{array}$ & $\begin{array}{c}\text { NíVEL DE } \\
\text { EVIDÊNCIA } \\
\text { (NE) }\end{array}$ \\
\hline A1 & 2009 & Espanhol & $\begin{array}{c}\text { Descritivo, retrospectivo e } \\
\text { transversal }\end{array}$ & Lilacs & IV \\
\hline A2 & 2018 & Espanhol & $\begin{array}{c}\text { Descritivo, observacional e } \\
\text { longitudinal }\end{array}$ & Lilacs & IV \\
\hline A3 & 2017 & Espanhol & $\begin{array}{c}\text { Descritiva, abordagem } \\
\text { quantitativa }\end{array}$ & Lilacs & V \\
\hline A4 & 2012 & Inglês & $\begin{array}{c}\text { Transversal, de dados } \\
\text { retrospectivos }\end{array}$ & Pubmed & IV \\
\hline A5 & 2008 & Inglês & Descritivo, retrospectivo & Lilacs & IV \\
\hline A6 & 2006 & Português & $\begin{array}{c}\text { Descritivo, retrospectivo, } \\
\text { quantitivo }\end{array}$ & Lilacs & IV \\
\hline A7 & 2006 & Inglês & Descritivo & Pubmed & IV \\
\hline A8 & 2019 & Inglês & Revisão retrospectiva & Pubmed & IV \\
\hline A9 & 2007 & Inglês & $\begin{array}{c}\text { Estudo de caso, descritivo } \\
\text { Fonte: Dados da pesquisa, 2020. }\end{array}$ & Pubmed & IV \\
\hline
\end{tabular}

Dos achados, $11,1 \%$ correspondiam à temática corpos estranhos em olhos; $33,3 \%$ em boca e/ou garganta; $11,1 \%$ no ouvido; $33,3 \%$ no nariz. E, $11,1 \%$ tratavam mutuamente de todas as temáticas.

Sobre o idioma, a prevalência foi o inglês $(55,5 \%)$, seguida espanhol $(33,3 \%$ ) e português $(11,1 \%)$. O periódico mais utilizado foi o Lilacs, correspondendo a 55,5\% da amostra e Pubmed com 44,4\%. Ressalta-se que nos anos de 2006 e 2017 foram encontrados dois artigos, respectivamente, e os demais anos de publicações apenas um em cada ano. 
No que diz respeito ao Nível de Evidência das publicações sumarizadas, obteve-se destaque o nível IV, seguidos por apenas um com nível V, o qual é justificado mediante a escassez de publicações e estudos sobre o temática.

A tabela 2 descreve as publicações selecionadas com os respectivos títulos, objetivos e principais resultados evidenciados.

Tabela 02: Distribuição da amostra do estudo segundo título, objetivo e principais resultados

\begin{tabular}{|c|c|c|}
\hline TITULO & OBJETIVO & PRINCIPAIS RESULTADOS \\
\hline $\begin{array}{l}\text { (A1) } \\
\text { Accidentes por } \\
\text { cuerpos extraños } \\
\text { en las vías } \\
\text { respiratorias } \\
\text { bajas em el niño. }\end{array}$ & 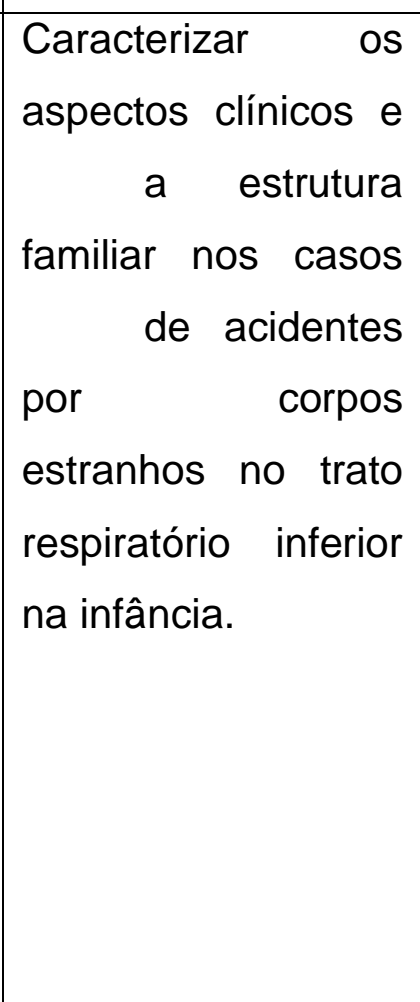 & $\begin{array}{l}\text { Caracterizou-se por crianças } \\
\text { menores de } 5 \text { anos }(66,7 \%) \text {, com } \\
\text { predomínio do sexo masculino } \\
(76,2 \%) \text {, no qual } 66,7 \% \text { dos acidentes } \\
\text { ocorreram em casa e } 83,3 \% \text { das } \\
\text { crianças tiveram acompanhamento } \\
\text { no momento do acidente. Os objetos } \\
\text { com maior incidência foram não- } \\
\text { orgânicos (52,4\%), e a localização } \\
\text { anatômica mais afetada foi o brônquio } \\
\text { direito (66,6\%). As principais } \\
\text { complicações foram atelectasia } \\
(21,4 \%) \text {, pneumonia (16,7\%) e óbito } \\
(2,3 \%) \text {. }\end{array}$ \\
\hline $\begin{array}{l}\text { (A2) } \\
\text { Caracterización } \\
\text { clinicoterapéutica } \\
\text { de niños y } \\
\text { adolescentes } \\
\text { com cuerpos } \\
\text { extraños aero } \\
\text { digestivos. }\end{array}$ & $\begin{array}{l}\text { Caracterizar as } 341 \\
\text { crianças } \\
\text { adolescentes } \\
\text { atendidos no pronto } \\
\text { atendimento por } \\
\text { apresentarem } \\
\text { corpos estranhos } \\
\text { aerodigestivos. }\end{array}$ & $\begin{array}{l}\text { Houve prevalência de menores de } 5 \\
\text { anos (62,5\%), sexo masculino } \\
(52,8 \%) \text {, origem urbana }(65,1 \%) \text {, } \\
\text { corpos estranhos orgânicos }(67,4 \%) \text {, } \\
\text { cavidade nasal como localização } \\
\text { anatômica, obstrução nasal como } \\
\text { principal sintoma e extração manual } \\
\text { por rinoscopia anterior. } \\
\text { Observaram-se corpos estranhos em } \\
11,1 \% \text { nos exames radiológicos. }\end{array}$ \\
\hline
\end{tabular}




\begin{tabular}{|c|c|c|}
\hline & & $\begin{array}{l}\text { Ressalta-se que um paciente morreu } \\
\text { durante o estudo. }\end{array}$ \\
\hline $\begin{array}{l}\text { (A3) } \\
\text { Peligro de asfixia: } \\
\text { conocimiento de } \\
\text { los padres sobre } \\
\text { laaspiración de } \\
\text { cuerpos extraños } \\
\text { niños. }\end{array}$ & $\begin{array}{l}\text { Avaliar o } \\
\text { conhecimento pais } \\
\text { sobre aspiração de } \\
\text { corpos estranhos } \\
\text { em crianças para } \\
\text { propor estratégias } \\
\text { de prevenção e } \\
\text { evitar novos } \\
\text { acidentes. }\end{array}$ & $\begin{array}{l}\text { Evidenciaram-se os objetos que } \\
\text { causavam mais asfixia em crianças } \\
\text { de } 1-3 \text { anos eram: moedas, } \\
\text { brinquedos e baterias. Os pais não } \\
\text { consideram tais objetos como níveis } \\
\text { de perigosidade para criança, bem } \\
\text { como não sabiam identificar os } \\
\text { principais sinais de asfixia na criança. }\end{array}$ \\
\hline $\begin{array}{l}\text { (A4) } \\
\text { Accidents with } \\
\text { foreign bodies in } \\
\text { children under } 15 \\
\text { years of age: } \\
\text { epidemiological } \\
\text { analysis of first } \\
\text { aid services, } \\
\text { hospitalizations, } \\
\text { and deaths }\end{array}$ & $\begin{array}{l}\text { Estudar a ocorrência } \\
\text { dos acidentes por } \\
\text { penetração em } \\
\text { orifício natural, } \\
\text { ingestão e inalação } \\
\text { de corpo estranho } \\
\text { entre menores de } 15 \\
\text { anos, residentes em } \\
\text { Londrina, Paraná, } \\
\text { Brasil }\end{array}$ & $\begin{array}{l}\text { Identificou-se predomínio do sexo } \\
\text { masculino (53,7\%), e o maior } \\
\text { coeficiente foi na faixa etária de } 1 \text { a } 3 \\
\text { anos (7,2 por mil crianças). A } \\
\text { penetração de corpo estranho em } \\
\text { orifício natural (olho, fossas nasais e } \\
\text { conduto auditivo) representou } 94 \% \text {, } \\
\text { seguida pela inalação e ingestão de } \\
\text { alimentos (2,8\%), pela inalação e } \\
\text { ingestão de outros objetos (2,5\%) e } \\
\text { pela inalação de conteúdo gástrico. }\end{array}$ \\
\hline $\begin{array}{l}\text { (A5) } \\
\text { Complications of } \\
\text { ent foreign } \\
\text { bodies: a } \\
\text { retrospectiv } \\
\text { estudy. }\end{array}$ & $\begin{array}{l}\text { Analisar, através de } \\
\text { um estudo } \\
\text { retrospectivo, } 1356 \\
\text { casos de corpos } \\
\text { estranhos } \\
\text { estabelecer causas } \\
\text { para } \\
\text { complicações, } \\
\text { objetivando medidas } \\
\text { preventivas. }\end{array}$ & $\begin{array}{l}\text { Evidenciou-se que, o corpo estranho } \\
\text { mais frequente foi o grão de feijão e a } \\
\text { faixa etária em destaque foi de } 1 \text { a } 4 \\
\text { anos. Corpos estranhos de orelha } \\
\text { foram os mais frequentes, seguidos } \\
\text { pelos de nariz. Complicações foram } \\
\text { estatisticamente relacionadas ao } \\
\text { tempo, faixa etária infantil e } \\
\text { experiência do médico. }\end{array}$ \\
\hline
\end{tabular}




\begin{tabular}{|c|c|c|}
\hline $\begin{array}{l}\text { (A6) } \\
\text { Corpos } \\
\text { estranhos de } \\
\text { fossas nasais: } \\
\text { descrição de } \\
\text { tipos } \quad \text { e } \\
\text { complicações em } \\
420 \text { casos. }\end{array}$ & $\begin{array}{l}\text { Avaliar um } \\
\text { total de } 420 \text { casos } \\
\text { de corpos estranhos } \\
\text { de fossas nasais } \\
\text { removidos r no } \\
\text { serviço de ORL- } \\
\text { EPO do Hospital } \\
\text { Municipal Souza } \\
\text { Aguiar, quanto a } \\
\text { vários parâmetros } \\
\text { como sexo, idade, } \\
\text { tipo e complicações. }\end{array}$ & $\begin{array}{l}\text { Os Identificou-se maior incidência na } \\
\text { faixa etária entre } 0 \text { a } 4 \text { anos, e os } \\
\text { copos estranhos mais encontrados } \\
\text { foram fragmentos de espuma, } \\
\text { material plástico de brinquedos, grãos } \\
\text { de feijão, e papel. Ocorrem } \\
\text { complicações em } 9,05 \% \text { dos casos, } \\
\text { sendo a epistaxe e a vestibulite as } \\
\text { mais comuns. }\end{array}$ \\
\hline $\begin{array}{l}\text { (A7) } \\
\text { Lower respiratory } \\
\text { tract } \\
\text { foreign bodies: a } \\
\text { retrospective } \\
\text { review } \\
\text { morbidity, } \\
\text { mortality and first } \\
\text { aid management. }\end{array}$ & $\begin{array}{lr}\text { Analisar } & \text { as } \\
\text { circunstâncias, } \\
\text { dificuldades } \\
\text { diagnósticas } \quad \text { e } \\
\text { tratamento inicial } \\
\text { de corpos estranhos } \\
\text { graves. }\end{array}$ & $\begin{array}{l}\text { A ineficiência dos métodos de } \\
\text { extração externa, como a manobra de } \\
\text { Heimlich, e o atraso médio entre os } \\
\text { sinais clínicos e o tratamento inicial } \\
\text { levou a propor uma nova estratégia } \\
\text { para o tratamento emergencial de } \\
\text { corpos estranhos com asfixia. }\end{array}$ \\
\hline $\begin{array}{l}\text { (A8) } \\
\text { Inhaled Foreign } \\
\text { Body Impaction: } \\
\text { A Review of } \\
\text { Literature in } \\
\text { Malaysian } \\
\text { Children }\end{array}$ & $\begin{array}{lr}\text { Caracterizar } & \text { na } \\
\text { literatura r os } \\
\text { principais } & \text { achados } \\
\text { sobre o impacto por } \\
\text { corpo estranho } \\
\text { inalado. }\end{array}$ & $\begin{array}{l}\text { A incidência de ingestão de corpos } \\
\text { estranhos em crianças variou com as } \\
\text { práticas alimentares. O amendoim foi } \\
\text { à substância alimentar mais comum } \\
\text { inalada, seguida por sementes de } \\
\text { melancia e caroço de coco. As } \\
\text { substâncias não relacionadas a } \\
\text { alimentos mais comuns foram objetos } \\
\text { de metal (brinquedos, molas, } \\
\text { grampos de cabelo) e objetos de } \\
\text { plástico (esferográficas, bonés e } \\
\text { apitos). A incidência de inalação de } \\
\text { substâncias relacionadas a alimentos }\end{array}$ \\
\hline
\end{tabular}




\begin{tabular}{|c|c|c|}
\hline & & $\begin{array}{l}\text { foi mais comum que a substância não } \\
\text { relacionada a alimentos. }\end{array}$ \\
\hline $\begin{array}{l}\text { (A9) } \\
\text { Corneal injury } \\
\text { from a metallic } \\
\text { foreign body: an } \\
\text { occupational } \\
\text { hazard. }\end{array}$ & 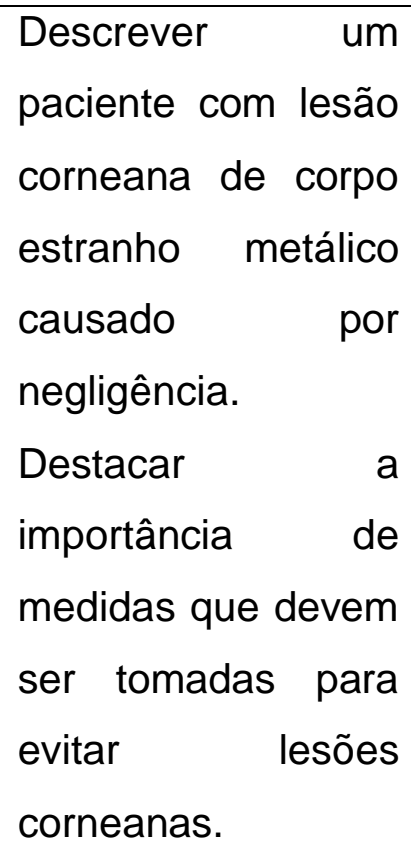 & $\begin{array}{l}\text { Um homem de } 21 \text { anos experimentou } \\
\text { uma sensação de corpo estranho, dor } \\
\text { e vermelhidão no olho esquerdo } \\
\text { depois de cortar algum material de } \\
\text { ferro sem usar proteção ocular. O } \\
\text { exame da lâmpada de fenda mostrou } \\
\text { um pedaço fino e enrolado de material } \\
\text { de ferro preso na córnea } \\
\text { horizontalmente. Após a remoção do } \\
\text { corpo estranho, a córnea cicatrizou } \\
\text { sem cicatrizes após um curto } \\
\text { acompanhamento. }\end{array}$ \\
\hline
\end{tabular}

Conforme a tabela 2, com base no recrutamento do material e agrupamento das temáticas expostas, foi elaborada quatro categorias de análise: I - Medidas de primeiros socorros a corpos estranhos nos olhos; II Medidas de primeiros socorros a corpos estranhos na boca e garganta; III Medidas de primeiros socorros a corpos estranhos no nariz; IV - Medidas de primeiros socorros a corpos estranhos nos ouvidos.

\section{Categoria I - Medidas de primeiros socorros a corpos estranhos nos olhos}

Com análise dos estudos, observou-se que os acidentes com corpos estranhos foram responsáveis por até $87 \%$ dos números de internações e atendimentos. $A$ faixa etária mais prevalente foi a infantil, com maior incidência entre 1-3 anos. Dos sintomas mais relatados, destacam-se: dor e vermelhidão. Quanto à origem do corpo estranho, mostraram-se como inconclusivas ou indeterminadas, relacionadas principalmente a atividades de recreação sem monitoramento do cuidador ou responsável.

As urgências oftalmológicas são importantes causas de morbidade na população, acarretando custos de ordem social, psicológica e econômica. Caracterizando-se como uma importante causa de comprometimento visual 
principalmente em indivíduos jovens, onde grande parte deles está relacionada a acidentes de trabalho na ausência de medidas preventivas. $O$ trauma nos olhos atinge o globo ocular e seus anexos, podendo ter origem mecânica, química, térmica ou elétrica sendo os três iniciais, pontualmente associados a presença de corpos estranhos como causador principal (CABRAL et al., 2013).

No tocante das medidas de primeiros socorros, ao prestar socorro à vítima com corpo estranho no olhos, deve-se inicialmente, acalmá-la, reconhecer o objeto e localizá-lo visualmente. Em seguida, pedir que a vítima faça repetidamente o movimento de fechar e abrir os olhos, na intenção do reflexo lacrimal remover o objeto. Caso a vítima relate dor ao fazer isso, interrompe-se a manobra, cobrindo o olho com um tampão sem comprimí-lo e encaminhar ao serviço de pronto atendimento mais próximo, na tentativa de diminuir qualquer lesão oriunda desse objeto (SANTOS, et al., 2016; SILVA; COSTA; ALBUQUERQUE, 2017).

Entretanto, caso o objeto esteja localizado na pálpebra móvel inferior, expondo a conjuntiva utiliza-se uma haste flexível com a ponta de algodão ou lenço umedecido para retirá-lo sem ocasionar pressão. Se o corpo estranho se trata de algum líquido, lava-se com água corrente por um tempo aproximado de 15 minutos, cobrindo em seguida com gaze ou pano limpo e conduzir a vítima ao serviço de saúde disponível (BRASIL, 2020; SANTOS, et al., 2016).

\section{Categoria II - Medidas de primeiros socorros a corpos estranhos na boca e garganta}

Os acidentes com corpos estranhos na cavidade oral e garganta, são ocorrências consideradas comuns, principalmente, se levado em consideração a distribuição por faixas etárias, no qual a predominância é de crianças de 1 a 10 anos, que devido à falta de atenção dos pais, seja na supervisão ou na manipulação dos alimentos, possibilitam as crianças o espaço para introduzirem partes de brinquedos, grãos, moedas e alimentos resultando no engasgo. Apesar de comuns e trazerem complicações sérias, são considerados de fácil eliminação, podendo ser expelidos por meio de mecanismos fisiológicos como a tosse e reflexos nauseosos (SBP, 2014; RODRIGUEZ et al., 2017; GARDEH et al., 2019). 
Uma vez presente na cavidade oral e/ou garganta as condutas de primeiros socorros traçadas para retirada desses corpos estranhos consistem em acalmar a vítima para que ela se tranquilize e respire fundo, e assim seja possível identificar de que corpo estranho se trata, realizar compressões abdominais e torácicas, e a tapotagem. É possível realizar ainda a manobra de Helmlich, caso a pessoa que vá realizá-la tenha o conhecimento de como executá-la corretamente (SANTOS, et al., 2016; SILVA; COSTA; ALBUQUERQUE, 2017; RUIZ, et al., 2018).

Se a vítima estiver inconsciente, deve-se posicioná-la em decúbito dorsal e ajoelhar-se ao lado vítima com sua face voltada para a dela. Logo após, colocar uma de suas mãos na linha média, um pouco acima da cicatriiz umbilical e abaixo do processo xifóide, sobrepondo a segunda mão sobre a primeira e realizando compressões com golpes rápidos e para cima. Se o corpo estranho não foi expelido ou a vítima ainda permanecer inconsciente, deve-se encaminhá-la ao pronto atendimento mais próximo rapidamente (SILVA; COSTA; ALBUQUERQUE, 2017; RUIZ,.et al, 2018).

\section{Categoria III - Medidas de primeiros socorros a corpos estranhos no nariz}

Os corpos na cavidade nasal, são comumente encontrados em ocorrências nos prontos atendimento, sendo mais comuns em crianças, jovens e pacientes psiquiátricos. Podendo ser por ações acidentais como a entrada de insetos ou deslocamento de objetos da oro ou rinofaringe, sendo estes casos corriqueiros para adultos. Como também por ações propositais, no caso das crianças ao introduzirem objetos na cavidade nasal (PULCHERIO et al., 2017).

A sintomatologia desses incidentes é caracterizada por espirros, coriza, obstrução nasal, rinorréria e epistaxe, onde quanto maior for o tempo de permanência daquele objeto, maior será a secreção purulenta e o odor fétido. A forma e o tamanho do corpo estranho é o que vai definir a dificuldade ou não que o procedimento de remoção trará. Tendo como algumas possíveis complicações, a perfuração septal e a broncoaspiração do objeto (GAMÉZ et al., 2009).

Nesses casos as medidas de primeiros socorros a serem seguidas baseiam-se em, inicialmente, acalmar a vítima para que não inale o corpo estranho ou dificulte a retirada, e após tranquilizá-la orienta-se que com uma de 
suas mãos comprima a narina que não está obstruída na tentativa que a pressão exercida contra a outra narina expulse o corpo estranho. Ressalta-se que se 0 corpo estranho ainda não foi expelido com a conduta mencionada, deve-se direcionar a vítima para os serviço de pronto atendimento mais próximo, afim de que não aconteça uma remoção errada, acarretando possiveis complicações (SILVA; COSTA; ALBUQUERQUE, 2017).

\section{Categoria IV - Medidas de primeiros socorros a corpos estranhos nos ouvidos}

Nos ouvidos, os corpos estranhos, mais encontrados são os insetos, dentre eles: às baratas que estão associadas a quem dorme no chão, seja por opção ou por necessidade. A presença de sementes, grãos de cereais e pequenas pedras são mencionadas na literatura como corpos estranhos que também podem causar perturbação e desconforto auditivo (SANTOS, et al., 2016).

Em domicílio, os primeiros socorros consistem em tranquilizar a vítima, deitá-la em decúbito lateral, no qual o ouvido afetado esteja para cima e se o corpo estranho estiver visível e não esteja profundo, tentar removê-lo, cuidadosamente, sem empurrá-lo para dentro do canal auditivo. Orienta-se a não utilizar objetos como pinças para a remoção, a fim de evitar lesões no ouvido da vítima. Em casos que o corpo estranho é um inseto, orienta-se que em um ambiente de pouca luminosidade, com o auxílio de uma lanterna aproximando-a ao meato auditivo externo atraia-se o inseto para fora. Se executadas as condutas já citadas o corpo estranho não foi removido encaminhar a vítima ao pronto atendimento mais próximo (SILVA; COSTA; ALBUQUERQUE, 2017; BRASIL, 2020).

\section{Conclusão}

O presente estudo permitiu demostrar a amplitude sobre a temática acidentes com corpos estranhos, descrevendo e categorizando as medidas de primeiros socorros em olhos, boca e garganta, nariz e ouvidos a serem seguidas, no intuito de diminuir eventuais riscos de complicações. 
Destaca-se nas publicações selecionadas as manifestações clínicas, epidemiologia e periocidade, a incidência entre faixas etárias, e que seja de forma acidental ou proposital.

Foi possível observar que há uma escassez de estudos nessa área, resultando assim, em uma pesquisa de difícil busca, porém, mesmo diante de tais problemas, encontram-se as condutas necessárias, os principais acidentes, e as faixas etárias mais atingidas, sendo informações significativas para agregar novos conhecimentos e construção desta produção científica em formato de revisão integrativa.

\section{Referências}

AMARAL, Jesislei Bonolo et al. Caracterização dos casos de óbito acidental de crianças por aspiração de corpos estranhos em Minas Gerais. Reme. Minas Gerais, v.23, n.1, p.1218-1223, 2019. Disponível em: < https://www.reme.org.br/artigo/detalhes/1364> . Acesso em: 16. abr. 2020.

BRASIL. Secretaria Municipal de Saúde. Departamento de Atenção à Saúde das Pessoas. Divisão de Enfermagem. Manual: Procedimentos Operacionais Padrão POPs / Secretaria Municipal de Saúde. Departamento de Atenção à Saúde das Pessoas. Divisão de Enfermagem. Ribeirão Preto: Prefeitura Municipal de Ribeirão Preto, 2020. Acesso em: 29 abr. 2020

CABRAL, Leonardo Almeida et al. Traumas oculares no serviço de urgência da Fundação Banco de Olhos de Goiás. Rev. bras.oftalmol. Rio de Janeiro, v. 72, n. 6, p. 383-387, dez., 2013 Disponível em: http://www.scielo.br/scielo.php?script=sci arttext\&pid=S0034 72802013000600006\&lng=en\&nrm=iso . Acesso em: 29 abr. 2020.

FIGUEIREDO, Ricardo Rodrigues et. al. Corpos estranhos de fossas nasais: descrição de tipos e complicações em 420 casos. Revista Brasileira de Otorrinolaringologia. Rio de Janeiro, v. 72 , n. 1, 2006. Disponível em: http://www.scielo.br/scielo.php?script=sci arttext\&pid=S0034- 72992006000100004 . Acesso em: 09. abr. 2020.

RAGADALI FILHO, Ragadali et al. A Importância do Treinamento de Primeiros Socorros no Trabalho. Revista Saberes. São Paulo, vol. 3, n. 2, jul./dez., p. 114-125, 2015. Disponível em: < https://facsaopaulo.edu.br/wpcontent/uploads/sites/16/2018/05/ed3/10.pdf> . Acesso em: 16. abr. 2020.

GAMÉZ, Haydée María Cantillo et. al. Accidentes por cuerpos extranõs em las vias respiratórias bajas en el niño. Revista Cubana Pediátrica. Habana-Cuba, v. 81, n. 3, jul./set., 2009. Disponível em:< http://scielo.sld.cu/pdf/ped/v81n3/ped04309.pdf>. Acesso em: 09. abr. 2020.

GENDEH, Haydée María Cantillo et al. Inhaled Foreign Body Impaction: A Review of Literature in Malaysian Children. The Indian Journal of Pediatrics. Kuala LumpurMalasya, v.86, n.1, p.20-24, 2019. Disponível em: < https://link.springer.com/article/10.1007/s12098-018-2824-8>. Acesso em: 09. abr.2020 
GUMUS, Koral; KARAKUCUK, Sarper; MIRZA Ertugrul. Corneal injury from a metallic foreign body: an occupational hazard. Eye Contact Lens. Sydney-Australia, v.5, n.33, p.259-260, 2007. Disponível em:< https://www.ncbi.nlm.nih.gov/pubmed/17873630 Acesso em: 10. abr.2020

MEIRELES, Glaucia Oliveira Abreu Batista. A abordagem de Primeiros Socorros Realizada Pelos Professores em uma Unidade de Ensino Estadual em Anápolis - GO. Ensaios Cienc., Cienc. Biol. Agrar. Saúde. Anápolis, v. 18, n. 1, p. 25-30, 2014. Disponível em: https://www.redalyc.org/pdf/260/26037787004.pdf . Acesso em: 16. abr. 2020.

MELNYK, Bernadette; FINEOCT-OVERHOLT, Ellen. Evidence-based practice in nursing and healthcare: a guide to best practice. 1 ed. Philadelphia: Lippincott Williams and Wilkins, 2005.

MENDES, Karina Dal Sasso; SILVEIRA, Renata Cristina de Campos Pereira; GALVÃO, Cristina Maria. Revisão integrativa: método de pesquisa para a incorporação de evidências na saúde e na enfermagem. Texto Contexto Enferm. Florianópolis, v.4, n.17, p.758-764, out.-dez, 2008. Disponível em: http://www.scielo.br/pdf/tce/v17n4/18.pdf . Acesso em: 09. abr. 2020.

PULCHERIO, Janaina Oliveira Bentivi et al. Foreign Bodies in Pediatric Patients: An Otolaryngologic Urgency?. Arch Pediatr. São Luiz, v.17, n.2, p.1-4, dez. 2017. Disponivel em:

https://www.gavinpublishers.com/admin/assets/articles pdf/1510643086article pdf697 442998.pdf> . Acesso em: 29 abr.2020

RODRÍGUEZ, Hugo et al. Peligro de asfixia: conocimiento de los padres sobre la aspiración de cuerpos extraños em niños. Revista Faso. Buenos Ares-Argentina, v. 24, n. 1., 2017. Disponível em: < http://faso.org.ar/revistas/2017/1/9.pdf > Acesso em: 09. abr. 2020.

RUIZ, Ariadna Elvia Cardero et al. Caracterización clínico terapéutica de niños y adolescentes com cuerpos extraños aero digestivos. Revista Medisan. Santiago-Cuba, v. 22, n. 4, abri. 2018. Disponível em: http://scielo.sld.cu/pdf/san/v22n4/san08224.pdf > Acesso em: 09. abr. 2020.

SANTOS, Wallison Pereira et al. Primeiros socorros na deposição de corpos estranhos nos olhos, ouvido, nariz e garganta. Educação ciência e Saúde. Cuité, v.3, n.1, p.7080, jan-Jun., 2016. Disponível em:< http://periodicos.ces.ufcg.edu.br/periodicos/index.php/99cienciaeducacaosaude25/artic le/view/66/pdf 22 >. Acesso em: 20 abr. 2020

SILVA, Rizocele; COSTA, Vivianny Beatriz Silva; ALBUQUERQUE, Adriana Montenegro de. Primeiros socorros na retirada de corpos estranhos nos olhos, ouvido, nariz e garganta: revisão integrativa. Educ. Ciência e Saúde. Cuité, v. 4, n. 1, p. 84-99, jan./jun., $2017 . \quad$ Disponível em:< http://periodicos.ces.ufcg.edu.br/periodicos/index.php/99cienciaeducacaosaude25/artic le/view/79/pdf 36 >. Acesso em: 09. abr. 2020

SOCIEDADE BRASILEIRA DE PEDIATRIA (SBP). Aspiração de corpo estranho.Rio de Janeiro. Disponível em: < https://www.sbp.com.br/imprensa/detalhe/nid/aspiracaode-corpo-estranho/ >. Acesso em: 29 abr. 2020. 
SOUZA, Marcela Tavares; SILVA, Michelly Dias; CARVALHO, Rachel .Revisão integrativa: o que é e como fazer. Einstein. São Paulo, v.1, n.8, p.102-106, 2010. Disponível em:http://www.scielo.br/pdf/eins/v8n1/pt 1679-4508-eins-8-1-0102.pdf Acesso em: 09. abr. 2020. 